\title{
Development of Body Mass Index of Japanese Triplets From Birth Until the Onset of Puberty
}

\section{Yokoyama, Yoshie}

2013-08

Yokoyama , Y , Pitkäniemi , J M , Kaprio , J \& Silventoinen , K 2013 , ' Development of Body Mass Index of Japanese Triplets From Birth Until the Onset of Puberty ' , Twin Research and Human Genetics , vol. 16 , no. 4 , pp. 861-868 . https://doi.org/10.1017/thg.2013.39

http://hdl.handle.net/10138/234288

https://doi.org/10.1017/thg.2013.39

publishedVersion

Downloaded from Helda, University of Helsinki institutional repository.

This is an electronic reprint of the original article.

This reprint may differ from the original in pagination and typographic detail.

Please cite the original version. 


\title{
Development of Body Mass Index of Japanese Triplets From Birth Until the Onset of Puberty
}

\author{
Yoshie Yokoyama, ${ }^{1}$ Janne Pitkäniemi, ${ }^{2}$ Jaakko Kaprio, ${ }^{2,3,4}$ and Karri Silventoinen ${ }^{5}$ \\ ${ }^{1}$ Department of Public Health Nursing, Osaka City University, Osaka, Japan \\ ${ }^{2} \mathrm{Hjelt}$ Institute, Department of Public Health, University of Helsinki, Helsinki, Finland \\ ${ }^{3}$ Department of Mental Health and Substance Abuse Services, National Institute for Health and Welfare, Helsinki, Finland \\ ${ }^{4}$ Institute for Molecular Medicine, University of Helsinki, Helsinki, Finland \\ ${ }^{5}$ Population Research Unit, Department of Social Research, University of Helsinki, Helsinki, Finland
}

\begin{abstract}
We aimed to analyze the characteristics of development of relative weight in Japanese triplets from birth until 12 years of age. Data were collected through a mailed questionnaire sent to mothers of triplets asking for information recorded in medical records. Altogether we had information on 1,061 triplet children of 354 mothers born between 1978 and 2006. For these births, data on triplets' height and weight growth, gestational age, sex, parity, and maternal age at delivery were obtained from records in the maternal and child health handbooks and records from the schools where children receive health check-ups. In addition, information on maternal height and weight was obtained. Triplets have a lower ponderal index at birth and lower body mass index (BMI) compared with the general population until 12 years of age, except for the period during 1 and 3 years of age. Moreover, birth weight had the strongest contribution to BMI of triplets until 6 years of age. After 9 years of age, maternal BMI was a significant factor affecting BMI of triplets.
\end{abstract}

Keywords: triplet, birth weight, maternal body mass index

It is well known that the growth patterns of twins and triplets during the third trimester of pregnancy differ from those of singletons because of a combination of the lack of space in the uterus in multiple pregnancies, intrauterine growth retardation, and shorter gestational age (Alexander et al., 1998; Glinianaia et al., 2000). Triplets are typically born prematurely, and $40-50 \%$ of them weigh less than 1,500 g at birth (Kato, 2004; Ziadeh, 2000). Previous studies have indicated that very low birth weight infants $(<1,500 \mathrm{~g})$ have significantly lower growth attainment in early and midchildhood than their normal birth weight peers (Finnstrom et al., 1998; Hack et al., 1996). Further follow-up in adolescence has shown that although there was some catch-up, these children continued to be smaller in size (Powls et al., 1996; Saigal et al., 2006). Meanwhile, several studies have reported that the differences in body size between twins and singletons at births disappeared during childhood, but in a few studies differences remained until adulthood (Buckler \& Green, 2004; Estourgie-van Burk et al., 2010, 2006; Luke et al., 1995; Pietiläinen et al., 1999; Wilson, 1979). Both weight and height of triplets were also found to be behind singletons until 12 years of age, in spite of the rapid catchup growth during the first year of life (Luke et al.; 2006; Yokoyama et al., 2011, 2012).
The special features of multiple pregnancies have further potential effects on the lives of triplets as it has been indicated that both low birth weight and shorter gestational age are risk factors for adverse health and neurodevelopmental outcomes (Arnoudse-Moens et al., 2009; Bhutta et al., 2002; Wadhawan et al., 2011). In addition, several studies have reported that intrauterine growth retardation is associated with an increased prevalence for development of adult diseases such as cardiovascular and metabolic derangements (Fall et al., 1995; Godfrey \& Barker, 2000); specifically, early growth failure (Singhal et al., 2003), and subsequent accelerated increase in weight gain and body mass index (BMI) during adolescence and adulthood (Bhargava et al., 2004; Eriksson et al., 2001; Loaiza \& Atalah, 2012).

RECEIVED 15 November 2012; ACCEPTED 6 May 2013. First published online 13 June 2013.

ADDRESS FOR CORRESPONDENCE: Yoshie Yokoyama, Department of Public Health Nursing, Osaka City University, Osaka, Japan. E-mail: yyokoyama@nurs.osaka-cu.ac.jp 
Studies of the long-term growth of low birth weight infants, including triplets (the majority of whom experience intrauterine and/or neonatal growth failure), may yield important information in this regard (Bukowski et al., 2001; Ehrenkranz et al., 1999). There is a paucity of studies on the postnatal growth of triplets in the world. The purpose of this study was to analyze the characteristics of prepubertal development of relative weight to height in Japanese triplets.

\section{Participants and Methods}

The participants in this study were recruited from the West Japan twins and higher-order multiple births registry (Yokoyama, 2013), which consisted of 578 mothers with triplets who were born between 1978 and 2006. Mothers and their triplet children were also enrolled from several other sources, such as various Japanese mothers' organizations for higher-order multiple births and referrals from public health centers.

Data were collected through a mailed questionnaire sent to the mothers asking for information available in medical records. For these births, data on triplets' weight and height growth, gestational age, sex, parity, and maternal age at delivery were obtained from the records in the Maternal and Child Health Handbooks. This handbook was established by the Maternal and Child Health Law in Japan and is provided to the expectant mother by the authorities following the report of pregnancy. The purpose of the handbook is to aid the maintenance of maternal and child health, and it includes information on health check-ups during pregnancy, the condition of the newborn, the progress of infant growth, and periodic medical check-ups for the infant and vaccinations recorded by obstetricians or pediatricians. In addition, information on maternal weight, height, and infertility treatment was obtained. For maternal BMI we used the categories of the Japan Society for the Study of Obesity, based on the definitions given by the World Health Organization (WHO Expert Committee, 1995): a BMI of less than $18.5 \mathrm{~kg} / \mathrm{m}^{2}$ as underweight; BMI of $18.5-24.9 \mathrm{~kg} / \mathrm{m}^{2}$ as normal; and BMI of more than $25 \mathrm{~kg} / \mathrm{m}^{2}$ as overweight or obese.

In Japan, the health check-up system after birth varies according to life stage. Until 6 years of age, children participate in health check-ups based on age, which is counted as actual weeks, months, or years after birth, administered by the Ministry of Health, Labor and Welfare. The height and weight data of children based on health check-ups are routinely recorded in the handbook. After 6 years of age, Japanese children receive health check-ups administered by the Ministry of Education, Culture, Sports, Science and Technology (2009) under the School Health Law. The height and weight measures from these school-based health check-ups are routinely recorded in the school records and made available to each family. Mothers have access to the school records from every grade and can check them directly. Mothers participating in this study were advised to refer to these records when completing the questionnaire.

The height and weight growth data were assigned to the appropriate age groups on the basis of time (in days) since birth, which was calculated as the date at the check-up minus the child's birthday. These data were semi-longitudinal. Specifically, data on the same individual were used according to the recorded times. Some of the children provided most of longitudinal data. On the other hand, others provided data from birth to six years of age. Additionally, the number of participants in each age group varied considerably as some children were younger than 12 years at the time of the survey. Consequently, the range of measurements in each group becomes smaller, especially at 12 years of age. However, as the mothers reported the growth of their children retrospectively, based on records, there is no age-related dropout in our data.

The response rate was $67.0 \%$. We had information on growth from 1,164 triplet children, but 103 children with unknown sex or height or weight were excluded from the analyses. Ultimately, the participants in this study were 354 mothers and their 1,061 triplet children. The mothers gave written informed consent to participate in the present study.

We used ponderal index $\left(\mathrm{kg} / \mathrm{m}^{3}\right)$ at birth and BMI $\left(\mathrm{kg} / \mathrm{m}^{2}\right)$ from 1 to 12 years of age as the indicators of relative weight, as suggested by Cole et al. (1997). The significance of differences between mean values of gestational age was tested using ANOVA where the comparison was between the three groups of maternal BMI. The means and standard deviations of ponderal index at birth and BMI from 1 to 12 years of age for triplets were calculated according to age and sex. The means and standard deviations of ponderal index at birth and BMI at 3, 6, 9, and 12 years of age for triplets were calculated according to gestational age, birth weight, birth length, parity, birth order, maternal age at triplet delivery, and maternal BMI. The significance of differences between mean values of ponderal index and BMI was tested using mix-model ANOVA, where the comparison was between two or more groups in order to adjust for familial clustering (i.e., sets of triplets) as a random effect factor. We fitted series of linear mixed effects models, and the statistical significance of regression coefficients of the interesting covariates (sex, birth order of triplets, gestational age, birth weight, birth length, or maternal BMI) was assessed from the fixed effects while adjusting for familial clustering (i.e., sets of triplets) by introducing shared random effect in the linear mixed model. The associations of the covariates with BMI of triplets at 3, 6, 9, or 12 years of age as outcome variables were explored by separate linear mixed effects model at a given age.

The ponderal index and BMI of the general population were calculated using mean values of the growth standards (height and weight) presented by the Ministry of Health, Labor and Welfare (Kato et al., 2001) and the Ministry of 


\section{TABLE 1}

Major Characteristics of the Triplet Individuals

\begin{tabular}{|c|c|}
\hline Variable & $N(\%)$ \\
\hline \multicolumn{2}{|l|}{ Gestational age (weeks) } \\
\hline$\leq 28$ & $66(6.2 \%)$ \\
\hline $29-32$ & $288(27.1 \%)$ \\
\hline $33-36$ & $603(56.8 \%)$ \\
\hline$\leq 37$ & $92(8.7 \%)$ \\
\hline Ūnknown & $12(1.1 \%)$ \\
\hline Mean \pm standard deviation & $33.1 \pm 2.65$ \\
\hline Range & $25-38$ \\
\hline \multicolumn{2}{|l|}{ Birth weight (g) } \\
\hline$<1,000$ & $74(7.0 \%)$ \\
\hline $1,000 \leq a<1,500$ & $252(23.8 \%)$ \\
\hline $1,500 \leq a<2,000$ & $491(46.3 \%)$ \\
\hline $2,000 \leq a<2,500$ & $214(20.2 \%)$ \\
\hline$\leq 2,500$ & $30(2.8 \%)$ \\
\hline Mean \pm standard deviation & $1,693.2 \pm 428.6$ \\
\hline Range & $574-3078$ \\
\hline \multicolumn{2}{|l|}{ Sex } \\
\hline Male & $534(50.3 \%)$ \\
\hline Female & $527(49.7 \%)$ \\
\hline \multicolumn{2}{|l|}{ Maternal parity at triplet birth } \\
\hline Nullipara & $829(78.1 \%)$ \\
\hline Multipara & $226(21.3 \%)$ \\
\hline Unknown & $6(0.6 \%)$ \\
\hline \multicolumn{2}{|l|}{ Infertility treatment of parents } \\
\hline Not used & $190(17.9 \%)$ \\
\hline Used & $850(80.1 \%)$ \\
\hline Unknown & $21(2.0 \%)$ \\
\hline \multicolumn{2}{|l|}{ Maternal age of delivery } \\
\hline$<25$ & $24(2.3 \%)$ \\
\hline $25-29$ & $346(32.6 \%)$ \\
\hline $30-34$ & $517(48.7 \%)$ \\
\hline$\leq 35$ & $174(16.4 \%)$ \\
\hline $\bar{M}$ ean \pm standard deviation & $31.0 \pm 3.60$ \\
\hline Range & $20-42$ \\
\hline \multicolumn{2}{|l|}{ Maternal BMI } \\
\hline$<18.5$ & 87 (8.2\%) \\
\hline $18.5-24.9$ & 557 (52.5\%) \\
\hline$\leq 25.0$ & $75(7.1 \%)$ \\
\hline Ünknown & 342 (32.2\%) \\
\hline
\end{tabular}

Education, Culture, Sports, Science and Technology (2009). The PASW statistical package, version 20.0 for Windows (2012) was used for the statistical analysis.

\section{Results}

Table 1 summarizes the characteristics of the participants. The mean gestational age at birth in triplets was $33.1 \pm 2.65$ weeks. Of 1,061 triplets, $30.8 \%$ were very low birth weight infants. The average maternal age of delivery was $31.0 \pm$ 3.60 years. In mothers of triplets, $7.1 \%$ were women whose BMI was more than $25.0 \mathrm{~kg} / \mathrm{m}^{2}$. Gestational age at birth differed significantly by maternal BMI and was $31.6 \pm 3.0$ weeks in women whose BMI was less than $18.5 \mathrm{~kg} / \mathrm{m}^{2}, 33.4$ \pm 2.5 weeks in women whose BMI was $18.5-24.9 \mathrm{~kg} / \mathrm{m}^{2}$ and $33.0 \pm 3.2$ weeks in women whose BMI was more than $25.0 \mathrm{~kg} / \mathrm{m}^{2}$.

Table 2 presents the number of participants and the mean ponderal index at birth and BMI until 12 years of age by sex. The difference of mean ponderal index between the triplets and the general population was $-2.56 \mathrm{~kg} / \mathrm{m}^{3}$ in males and
$-2.29 \mathrm{~kg} / \mathrm{m}^{3}$ in females. After 1 year, the difference of BMI almost disappeared during the first year of life. However, this difference started to increase from 4 years of age and fluctuated between $-0.7 \mathrm{~kg} / \mathrm{m}^{2}$ and $-2 \mathrm{~kg} / \mathrm{m}^{2}$ from 5 until 12 years of age. At 8 years, the mean difference was -1.01 $\mathrm{kg} / \mathrm{m}^{2}$ for males and $-1.21 \mathrm{~kg} / \mathrm{m}^{2}$ for females.

The mean ponderal index at birth and BMI at 3, 6, 9, and 12 years of age were analyzed according to gestational age, birth weight, birth length, parity, birth order, maternal age at triplet delivery, and maternal BMI (Table 3). A low gestational age was associated with lower ponderal index at birth and lower BMI at 3, 6, 9, and 12 years of age; these differences were statistically significant. Low birth weight or low birth length were also associated with lower BMI at 3 , 6,9 , and 12 years of age. Third-born neonates had a lower ponderal index and lower BMI at 3 years of age. Triplets born to women whose BMI was lower had a lower ponderal index and lower BMI at 3, 9, and 12 years of age than triplet children born to women whose BMI was higher.

Table 4 shows the results of linear mixed effects multiple regression analysis of BMI of triplets at 3,6, 9, and 12 years of age. We also present regression coefficients and $p$ values for each covariate. Birth weight has the strongest contribution to the BMI of triplets at 3 and 6 years of age, but also birth length affected BMI at 3 and 6 years of age. Gestational age affected BMI at 3 years of age. Maternal BMI increased BMI of triplets at 9 and 12 years of age.

\section{Discussion}

In the present study, triplets have a lower ponderal index at birth and lower BMI from 4 until 12 years of age compared to the general population. However, we did not find any differences between triplets and general population for the period from 1 to 3 years of age. It is well known that twin and triplet pregnancies are characterized by earlier gestational age, lower birth weight, and rapid catch-up growth, especially during the first year of life (Buckler \& Green, 2004; Yokoyama et al., 2011, 2012). That there were no differences for BMI from 1 to 3 years of age between triplets and the general population may be because of rapid catch-up growth and special features of triplet pregnancies.

Meanwhile, the differences in BMI between triplets and the general population after 4 years of age are similar to those reported by Hack et al. (2003), who found that very low birth weight children had significantly lower BMI than their normal birth weight peers at 8 years of age, with a mean deficit of $1.5 \mathrm{~kg} / \mathrm{m}^{2}$ for males and $1.3 \mathrm{~kg} / \mathrm{m}^{2}$ for females. In addition, Saigal et al. (2006) found that in young adulthood, extremely low birth weight $(<1,000 \mathrm{~g})$ men and women were significantly smaller in height and weight compared with their peers, but BMI for both sexes showed no differences between the groups.

Several twin studies have reported that male twins have lower BMI in early adulthood than singletons (Pietiläinen 
TABLE 2

Number of Triplet Individuals and Means and Standard Deviations (SD) of Ponderal Index at Birth and Body Mass Index From 1 to 12 Years of Age by Sex

\begin{tabular}{|c|c|c|c|c|c|c|c|c|c|c|}
\hline & \multicolumn{3}{|c|}{ Male triplets } & \multirow{2}{*}{$\begin{array}{l}\begin{array}{l}\text { Reference } \\
\text { (male) }\end{array} \\
\text { Mean }\end{array}$} & \multirow{2}{*}{$\begin{array}{l}\text { Mean difference } \\
(95 \% \mathrm{Cl})\end{array}$} & \multicolumn{3}{|c|}{ Female triplets } & \multirow{2}{*}{$\begin{array}{l}\begin{array}{l}\text { Reference } \\
\text { (female) }\end{array} \\
\text { Mean }\end{array}$} & \multirow{2}{*}{$\begin{array}{l}\text { Mean difference } \\
(95 \% \mathrm{Cl})\end{array}$} \\
\hline & $N$ & Mean & $S D$ & & & $\mathrm{~N}$ & Mean & $S D$ & & \\
\hline Birth & 498 & 23.28 & 2.59 & $25.84^{*}$ & $-2.56(-2.79,-2.33)$ & 493 & 23.82 & 3.11 & $26.11^{*}$ & $-2.29(-2.57,-2.02)$ \\
\hline 1 year, 0-1 month & 180 & 16.64 & 1.25 & 16.68 & $-0.04(-0.22,0.15)$ & 164 & 16.35 & 1.42 & 16.30 & $0.05(-0.17,-0.27)$ \\
\hline 2 years, $0-6$ months & 241 & 16.17 & 1.28 & 15.91 & $0.26(0.10,0.43)$ & 236 & 15.85 & 1.35 & 15.62 & $0.23(0.06,-0.40)$ \\
\hline 3 years, $0-6$ months & 272 & 15.64 & 1.17 & 15.76 & $-0.12(-0.26,0.02)$ & 269 & 15.53 & 1.19 & 15.51 & $0.02(-0.12,0.16)$ \\
\hline 4 years, $0-6$ months & 193 & 15.28 & 1.07 & $15.65^{*}$ & $-0.37(-0.52,-0.22)$ & 185 & 15.19 & 1.51 & $15.42^{*}$ & $-0.23(-0.45,-0.01)$ \\
\hline 5 years, $0-6$ months & 185 & 14.98 & 1.15 & $15.71^{*}$ & $-0.73(-0.90,-0.56)$ & 192 & 14.75 & 1.26 & $15.48^{*}$ & $-0.73(-0.91,-0.56)$ \\
\hline 6 years, $0-6$ months & 191 & 14.88 & 1.33 & $15.81^{*}$ & $-0.93(-1.12,-0.74)$ & 183 & 14.67 & 1.25 & $15.66^{*}$ & $-0.99(-1.17,-0.81)$ \\
\hline 7 years, $0-6$ months & 132 & 15.40 & 1.62 & $16.13^{*}$ & $-0.73(-1.01,-0.46)$ & 120 & 14.89 & 1.40 & $15.89^{*}$ & $-1.00(-1.26,-0.75)$ \\
\hline 8 years, $0-6$ months & 118 & 15.66 & 1.91 & $16.67^{*}$ & $-1.01(-1.35,-0.67)$ & 102 & 15.18 & 1.61 & $16.39^{*}$ & $-1.21(-1.53,-0.90)$ \\
\hline 9 years, $0-6$ months & 104 & 16.02 & 2.46 & $17.20^{*}$ & $-1.18(-1.65,-0.70)$ & 106 & 15.61 & 1.86 & $16.83^{*}$ & $-1.22(-1.58,-0.87)$ \\
\hline 10 years, $0-6$ months & 88 & 16.49 & 2.75 & $17.80^{*}$ & $-1.31(-1.88,-0.73)$ & 85 & 15.80 & 1.90 & $17.45^{*}$ & $-1.65(-2.05,-1.25)$ \\
\hline 11 years, 0-6 months & 62 & 16.92 & 2.66 & $18.38^{*}$ & $-1.46(-2.12,-0.79)$ & 56 & 16.14 & 1.84 & $18.14^{*}$ & $-2.00(-2.49,-1.52)$ \\
\hline 12 years, $0-6$ months & 45 & 17.77 & 2.99 & $19.13^{*}$ & $-1.36(-2.24,-0.49)$ & 38 & 17.19 & 1.90 & $19.06^{*}$ & $-1.87(-2.48,-1.27)$ \\
\hline
\end{tabular}

Note: ${ }^{1}$ mean value of the general male population; ${ }^{2}$ mean value of the general female population; ${ }^{*} p<.05$.

\section{TABLE 3}

Descriptive Statistics of Ponderal Index at Birth and Body Mass Index at 3, 6, 9, and 12 Years of Age Among Japanese Triplets

\begin{tabular}{|c|c|c|c|c|c|c|c|c|c|c|c|c|c|c|c|}
\hline & \multicolumn{3}{|c|}{ Birth $\left(\mathrm{kg} / \mathrm{m}^{3}\right)$} & \multicolumn{3}{|c|}{$\begin{array}{c}\text { Three years of age } \\
\left(\mathrm{kg} / \mathrm{m}^{2}\right)\end{array}$} & \multicolumn{3}{|c|}{$\begin{array}{l}\text { Six years of age } \\
\left(\mathrm{kg} / \mathrm{m}^{2}\right)\end{array}$} & \multicolumn{3}{|c|}{$\begin{array}{l}\text { Nine years of age } \\
\left(\mathrm{kg} / \mathrm{m}^{2}\right)\end{array}$} & \multicolumn{3}{|c|}{$\begin{array}{l}\text { Twelve years of age } \\
\qquad\left(\mathrm{kg} / \mathrm{m}^{2}\right)\end{array}$} \\
\hline & $N$ & Mean & $S D$ & $N$ & Mean & $S D$ & $N$ & Mean & $S D$ & $N$ & Mean & $S D$ & $N$ & Mean & $S D$ \\
\hline \multicolumn{16}{|l|}{ Gestational age } \\
\hline$\leq 28$ & 59 & 23.08 & $3.14^{*}$ & 28 & 15.39 & $1.02^{*}$ & 19 & 14.19 & $1.21^{* *}$ & 7 & 13.90 & $1.34^{*}$ & 3 & 14.74 & $0.27^{* * *}$ \\
\hline $29-32$ & 263 & 23.25 & 3.16 & 167 & 15.38 & 1.16 & 108 & 14.51 & 1.18 & 62 & 15.47 & 2.10 & 18 & 15.78 & 1.95 \\
\hline $33-36$ & 577 & 23.64 & 2.74 & 291 & 15.68 & 1.18 & 205 & 14.93 & 1.37 & 127 & 16.00 & 2.18 & 47 & 17.89 & 1.96 \\
\hline$\leq 37$ & 80 & 24.34 & 2.50 & 52 & 15.70 & 1.20 & 42 & 15.01 & 1.04 & 14 & 16.58 & 2.42 & 15 & 18.89 & 3.59 \\
\hline \multicolumn{16}{|l|}{ Birth weight } \\
\hline$<1,000$ & 68 & 22.52 & $3.19^{* * *}$ & 40 & 14.80 & $1.05^{* * *}$ & 28 & 13.81 & $1.17^{* * *}$ & 11 & 14.10 & $2.01^{* * * *}$ & 3 & 14.26 & $1.74^{* *}$ \\
\hline $1,000 \leq a<1,500$ & 234 & 22.70 & 2.89 & 136 & 15.16 & 1.00 & 97 & 14.55 & 1.18 & 53 & 15.19 & 1.69 & 18 & 16.12 & 1.93 \\
\hline $1,500 \leq a<2,000$ & 461 & 23.62 & 2.66 & 258 & 15.71 & 1.13 & 160 & 14.73 & 1.18 & 101 & 15.87 & 1.99 & 29 & 17.62 & 1.75 \\
\hline $2,000 \leq a<2,500$ & 199 & 24.58 & 2.87 & 93 & 16.05 & 1.30 & 77 & 15.38 & 1.42 & 40 & 16.97 & 2.79 & 29 & 18.38 & 3.15 \\
\hline$\leq 2,500$ & 29 & 24.51 & 2.18 & 14 & 16.34 & 1.03 & 12 & 15.69 & 0.75 & 5 & 15.82 & 0.84 & 4 & 18.92 & 1.20 \\
\hline \multicolumn{16}{|l|}{ Birth length } \\
\hline $40<$ & 262 & 24.09 & $3.45^{* * *}$ & 144 & 15.14 & $1.11^{* * *}$ & 93 & 14.32 & $1.29 * * *$ & 51 & 15.05 & $1.89^{*}$ & 16 & 15.69 & $1.93^{* *}$ \\
\hline $40 \leq a<45$ & 549 & 23.57 & 2.68 & 275 & 15.71 & 1.06 & 194 & 14.89 & 1.13 & 110 & 16.05 & 2.16 & 31 & 18.20 & 2.67 \\
\hline$\leq 4 \overline{5}$ & 180 & 22.69 & 2.24 & 81 & 16.01 & 1.09 & 56 & 15.36 & 1.50 & 31 & 16.15 & 2.62 & 21 & 17.63 & 2.19 \\
\hline \multicolumn{16}{|l|}{ Maternal parity } \\
\hline Primipara & 771 & 23.52 & 2.86 & 431 & 15.60 & 1.21 & 295 & 14.70 & $1.27^{*}$ & 171 & 15.73 & 2.20 & 68 & 17.19 & $2.12^{*}$ \\
\hline Multipara & 214 & 23.49 & 2.73 & 107 & 15.49 & 1.08 & 76 & 15.09 & 1.35 & 36 & 16.26 & 2.19 & 15 & 18.91 & 3.76 \\
\hline \multicolumn{16}{|l|}{ Triplet birth order } \\
\hline First-born & 330 & 24.24 & $2.93^{* * *}$ & 181 & 15.61 & $1.09^{*}$ & 124 & 14.81 & $1.36^{*}$ & 72 & 15.96 & 2.45 & 28 & 17.60 & 2.49 \\
\hline Second-born & 331 & 23.37 & 2.76 & 181 & 15.72 & 1.29 & 124 & 14.92 & 1.34 & 67 & 16.06 & 2.05 & 28 & 17.89 & 2.79 \\
\hline Third-born & 330 & 23.03 & 2.78 & 179 & 15.42 & 1.14 & 126 & 14.60 & 1.15 & 71 & 15.43 & 2.00 & 27 & 16.99 & 2.37 \\
\hline \multicolumn{16}{|c|}{ Maternal age at Triplet delivery } \\
\hline$<25$ & 16 & 24.60 & 4.06 & 15 & 15.10 & 1.11 & 9 & 13.05 & $1.45^{* * *}$ & 3 & 14.07 & 0.54 & 3 & 17.08 & 0.76 \\
\hline $25-29$ & 320 & 23.53 & 3.03 & 169 & 15.64 & 1.37 & 93 & 14.85 & 1.22 & 64 & 15.97 & 2.14 & 25 & 17.42 & 2.70 \\
\hline $30-34$ & 490 & 23.60 & 2.81 & 282 & 15.61 & 1.10 & 208 & 14.80 & 1.31 & 119 & 15.62 & 2.19 & 42 & 17.71 & 2.79 \\
\hline$\leq 35$ & 165 & 23.32 & 2.57 & 75 & 15.44 & 1.00 & 64 & 14.85 & 1.17 & 24 & 16.58 & 2.23 & 13 & 17.10 & 1.72 \\
\hline \multicolumn{16}{|l|}{ Maternal BMI } \\
\hline$<18.5$ & 83 & 22.37 & $3.15^{* * *}$ & 57 & 15.13 & $1.15^{* *}$ & 48 & 14.38 & 1.13 & 25 & 14.64 & $1.45^{* *}$ & 6 & 14.98 & $1.91^{* * *}$ \\
\hline $18.5-24.9$ & 509 & 23.70 & 2.76 & 372 & 15.67 & 1.19 & 229 & 14.85 & 1.34 & 145 & 15.83 & 2.20 & 65 & 17.20 & 1.98 \\
\hline$\leq 25.0$ & 70 & 23.82 & 2.89 & 44 & 15.67 & 0.92 & 34 & 14.86 & 1.34 & 20 & 16.56 & 2.56 & 6 & 21.36 & 4.49 \\
\hline
\end{tabular}

Note: $S D=$ standard deviation; All variables included in the model.

$$
{ }^{*} p<.05 ;{ }^{* *} p<.01 ;{ }^{* * *} p<.001 \text {. }
$$

et al., 2002; Silventoinen et al., 2008). It has been indicated that these differences may have their origin in the prenatal conditions of twin pregnancies (Buckler \& Green, 2004). There are also differences in placentation between monozygotic (MZ) and dizygotic (DZ) twins, because while all DZ twins are dichorionic, about $60 \%$ of $\mathrm{MZ}$ pregnancies are monochorionic, which may lead to vascular abnormalities during pregnancy (Derom et al., 2005). The vascular abnormalities often result in large birth weight differences between MZ twins and may affect future growth (Pietiläinen et al., 2002). The prenatal conditions of triplets are more serious compared with those of twins (Glinianaia, et al., 


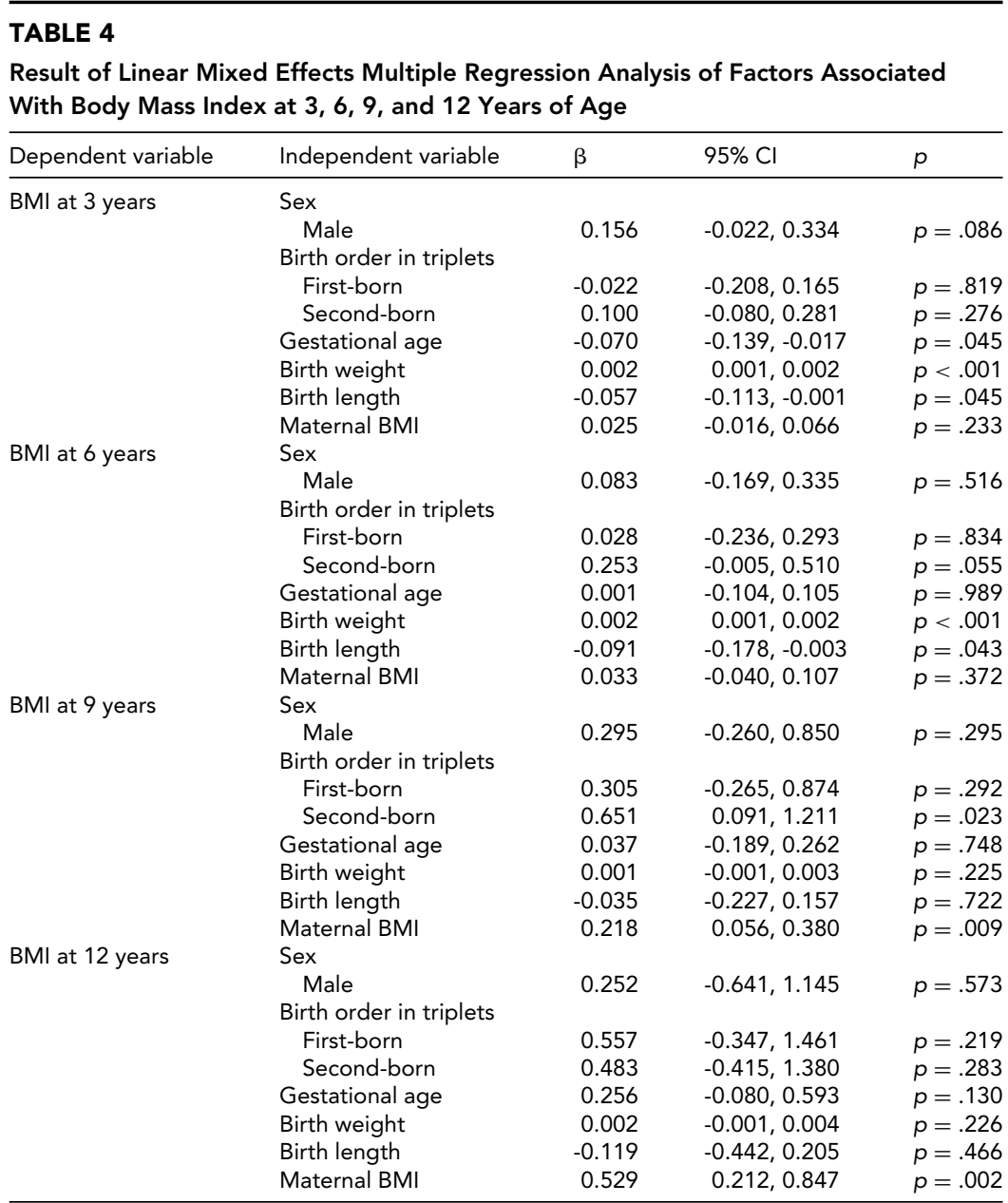

2000; Kato, 2004; Luke et al., 2002; Yokoyama et al., 2012). Further follow-up is needed to investigate whether triplets achieve normal body size, including BMI, later in life.

In the present study, when adjusting for gestational age and other confounding factors, birth weight had the strongest contribution to BMI of triplets at 3 and 6 years of age, but the influence disappeared at 9 years of age. Birth length also showed a similar trend. Saigal et al. (2006) and Hack et al. (2003) have indicated that catch-up growth for BMI occurs between 8 years of age and adolescence among very low birth weight or extremely low birth weight groups. Our study supports those results reported by Saigal et al. (2006) and Hack et al. (2003).

Furthermore, maternal BMI was a significant factor affecting BMI of triplets at 9 and 12 years of age. Parental obesity has been found to be one of the strongest risk factors for childhood obesity in singletons (Bundred et al., 2001; Burke, et al., 2001; James et al., 2001; Reilly \& Dorosty, 1999). In addition, it has been indicated that parental leanness confers significant protection against the development of overweight in children (Semmler et al., 2009). A Danish study reported that the BMI of adoptive children from 7 to 13 years of age correlated more strongly with biological relatives than adoptive relatives, suggesting that genetic factors are more important than common environmental factors (Sørensen et al., 2002). Twin studies have also indicated that childhood obesity has a major heritable component (Silventoinen \& Kaprio, 2009; Silventoinen et al., 2010), but also some non-genetic shared/familial component. Moreover, it was indicated in a longitudinal population-based cohort of male twins that BMI at age of 18 years correlated with BMI at age of 1 year, and this correlation increased steadily up to 17 years of age, mainly because of genetic effects (Silventoinen et al., 2007). In our study, the predicting power of maternal BMI steadily increased at later ages, probably indicating the increasing influence of genetic factors over environmental factors affecting their triplet children's BMI. These results suggest that maternal physique has a significant effect not only on physique in singletons during childhood, but also on that of triplets, probably reflecting the role of genetic factors masked in early life by the special features of triplet pregnancies but becoming visible in later life.

Regarding other factors associated with BMI of triplets, we found a small birth order effect: the third-born triplet had a lower BMI than the other triplets. Previous studies in twins have reported similar results at birth (Glinianaia et al., 2000) and from 3 to 12 years of age (Silventoinen et al., 2007). The background of this effect needs more detailed 
research, but in twins, the first-born (and heavier) twin was found to have a heavier placenta and a more optimal cord insertion (Gielen et al., 2007). Possibly, triplets higher in birth order are more optimally positioned with respect to intake of nutrients. The persistence of this birth order effect suggests that prenatal factors can have long-lasting effects on body size including BMI.

A limitation of the present study was that these data did not include information on the zygosity of the triplets. It has been indicated that zygosity affects the birth weight of triplets (Lamb et al., 2011), and this may influence future BMI. Data on paternal weight and height, maternal smoking, maternal weight gain during pregnancy, and feeding methods were also lacking in this study, and it has been suggested that these factors are associated with BMI (Eriksson et al., 2001; Lande et al., 2005; Ooki \& Yokoyama, 2004; Pirilä et al., 2012). Also, pubertal status was not assessed, and this may affect BMI at the last time point.

In conclusion, triplets have a lower ponderal index and lower BMI compared to the general population of Japan from birth to 12 years of age, except for the period from 1 to 3 years of age. Birth weight had the strongest contribution to BMI until 6 years of age. After 9 years of age, maternal BMI was found to be a significant factor affecting BMI. Further follow-up of the triplets should reveal whether their growth catches up with singletons before adulthood and which early factors predict variability in BMI in adolescence and young adulthood

\section{Acknowledgments}

The authors acknowledge the help of Kenka Lee in the data analysis. This research was supported by Ministry of Education, Science, Sports and Culture, Grant-in-Aid for Scientific Research (B), 2008-2012. The Academy of Finland Centre of Excellence in Complex Disease Genetics supported the participation of JK, KS, and JP. KS was additionally supported by the Academy of Finland (266592).

\section{References}

Alexander, G. R., Kogan, M., Martin, J., \& Papiernik, E. (1998). What are the fetal growth patterns of singletons, twins, and triplets in the United States? Clinical Obstetrics and Gynecology, 41, 114-125.

Arnoudse-Moens, C. S. H., Weisglas-Kuperus, N., van Goudoever, J. B., \& Oosterlaan, J. (2009). Metaanalysis of neurobehavioral outcomes in very preterm and/or very low birth weight children. Pediatrics, 124, $717-728$.

Bhargava, S. K., Sachdev, H. S., Fall, C. H., Osmond, C., Lakshmy, R., Barker, D. J., ... Reddy, K. S. (2004). Relation of serial changes in childhood body-mass index to impaired glucose tolerance in young adulthood. The New England Journal of Medicine, 350, 865-875.

Bhutta, A. T., Clevels, M. A., Casey, P. H., Cradok, M. M., \& Anand, K. J. S. (2002). Cognitive and behavioral outcomes of school-aged children who were born preterm - a meta analysis. JAMA, 288, 728-737.

Buckler, J. M., \& Green, M. (2004). A comparison of the early growth of twins and singletons. Annals of Human Biology, 31, 311-332.

Bukowski, R., Gahn, D., Denning, J., \& Saade, G. (2001). Impairment of growth in fetuses destined to deliver preterm. American Journal of Obstetrics and Gynecology, 185, 463467.

Bundred, P., Kitchner, D., \& Buchan, I. (2001). Prevalence of overweight and obese children between 1989 and 1998: Population based series of cross sectional studies. BMJ, 322, 326-328.

Burke, V., Bellin, L. J., \& Dunbar, D. (2001). Family lifestyle and parental body mass index as predictors of body mass index in Australian children: A longitudinal study. International Journal of Obesity and Related Metabolic Disorders, 25, 147157.

Cole, T. J., Henson, G. L., Tremble, J. M., \& Colley, N. V. (1997). Birthweight for length: ponderal index, body mass index or Benn index? Annals of Human Biology, 24, 289-298.

Derom, R., Derom, C., \& Vlietinck, R. (2005). Placentation. In I. Blickstein \& L. G. Keith (Eds.), Multiple pregnancy (2nd ed., pp. 157-167). London/New York: Taylor \& Francis.

Ehrenkranz, R. A., Younes, N., Lemons, J. A., Fanaroff, A. A., Donovan, E. F., Wright, L. L., . . Papile, L. A. (1999). Longitudinal growth of hospitalized very low-birth-weight infants. Pediatrics, 104, 280-289.

Eriksson, J., Forsén, T., Tuomilehto, J., Osmond, C., \& Barker, D. (2001). Size at birth, childhood growth and obesity in adult life. International Journal of Obesity and Related Metabolic Disorders, 25, 735-740.

Eriksson, J. G., Forsen, T., Tuomilehto, J., Osmond, C., \& Barker, D. J. (2001). Early growth and coronary heart disease in later life: Longitudinal study. BMJ, 322, 949-953.

Estourgie-van Burk, G. F., Bartels, M., Boomsma, D. I., \& Delemarre-van de Waal, H. A. (2010). Body size of twins compared with siblings and the general population: From birth to late adolescence. Journal of Pediatrics, 156, 586591.

Estourgie-van Burk, G. F., Bartels, M., van Beijsterveldt, T. C., Delemarre-van de Waal, H. A., \& Boomsma, D. I. (2006). Body size in five-year-old twins: Heritability and comparison to singleton standards. Twin Research and Human Genetics, 9, 646-655.

Fall, C. H. D., Osmond, C., Barker, D. J. P., Clark, P. M. S., Hales, C. N., Stirling, Y., \& Meade, T. W. (1995). Fetal and infant growth and cardiovascular risk factors in women. BMJ, 310, 428-432.

Finnstrom, O., Otterblad Olausson, P., Sedin, G., Serenius, F., Svenningsen, N., Thiringer, K, ... Wesstrom, G. (1998). Neurosensory outcome and growth at three years in extremely low birthweight infants: Follow-up results from the Swedish national prospective study. Acta Paediatrica, 87, 1055-1060.

Gielen, M., Lindsey, P. J., Derom, C., Loos, R. J. F., Derom, R., Nijhuis, J. G., \& Vlietinck, R. (2007). Twin birth weight standards. Neonatology, 92, 164-173. 
Glinianaia, S. V., Skjaerven, R., \& Magnus, P. (2000). Birth weight percentiles by gestational age in multiple births. A population-based study of Norwegian twins and triplets. Acta Obstetricia et Gynecologica Scandinavica, 79, 450458.

Godfrey, K. M., \& Barker, D. J. (2000). Fetal nutrition and adult disease. American Journal of Clinical Nutrition, 71(Suppl), 1344-1352.

Hack, M., Schluchter, M., Catar, L., Rahman, M., Cuttler, L., \& Borawski, E. (2003). Growth of very low birth weight infants to age 20 years. Pediatrics, 112, e30-e38.

Hack, M., Weissman, B., \& Borawski-Clark, E. (1996). Catchup growth during childhood among very low birthweight children. Archives of Pediatrics and Adolescent Medicine, 150, 1122-1129

James, P. T., Leach, R., Kalamara, E., \& Shayeghi, M. (2001). The worldwide obesity epidemic. Obesity Research, 9(Suppl. 4), 228-233.

Kato, N. (2004). Reference birthweight range for multiple birth neonates in Japan. BMC Pregnancy Childbirth, 4, 2.

Kato, N., Okuno, T., \& Takaishi, M. (2001). Comments on the results of growth standards of Japanese children in 2000. Shoni Hoken Kenkyu [Journal of Child Health], 60, 707720 .

Lamb, D. J., Middeldorp, C. M., van Beijsterveldt, C. E. M., Vink, J. M., Haak, M. C., \& Boomsma, D. I. (2011). Birth weight in a large series of triplets. BMC Pediatrics, 11, 1-11.

Lande, B., Andersen, L. F., Henriksen, T., Bærug, A., Johansson, L., Trygg, K., ... Veierød, M. B. (2005). Relations between high ponderal index at birth, feeding practices and body mass index in infancy. European Journal of Clinical Nutrition, 59, 1241-1249.

Loaiza, S., \& Atalah, E. (2012). Birth weight and obesity risk at first grade of high school in a non-concurrent cohort of Chilean children. Public Health Nutrition, 9, 1-5.

Luke, B., Brown, M. B., Hediger, M. L., Misiunas, R. B., \& Anderson, E. (2006). Perinatal and early childhood outcomes of twins versus triplets. Twin Research and Human Genetics, 9, 81-88.

Luke, B., Leurgans, S., Keith, L., \& Keith, D. (1995). The childhood growth of twin children. Acta Geneticae Medicae et Gemellologiae (Roma), 44, 169-178.

Luke, B., Nugent, C., van de Ven, C., Martin, D., O’Sullivan, M. J., Eardley, S., . . Newman, R. B. (2002). The association between maternal factors and perinatal outcomes in triplet pregnancies. American Journal of Obstetrics and Gynecology, 187, 752-757.

Ministry of Education, Culture, Sports, Science and Technology. (2009). Comment on the results of growth standards of Japanese children in 2008. Shoni Hoken Kenkyu [Journal of Child Health], 92, 92-124.

Ooki, S., \& Yokoyama, Y. (2004). Physical growth carts from birth to six years of age in Japanese twins. Journal of Epidemiology, 14, 151-160.

Pietiläinen, K. H., Kaprio, J., Räsänen, M., Rissanen, A., \& Rose, R. J. (2002). Genetic and environmental influences on the tracking of body size from birth to early adulthood. Obesity Research, 10, 875-884.
Pietiläinen, K. H., Kaprio, J., Rissanen, A., Winter, T., Rimpela, A., Viken, R. J., \& Rose, R. J. (1999). Distribution and heritability of BMI in Finnish adolescents aged 16y and 17y: A study of 4884 twins and 2509 singletons. International Journal of Obesity and Related Metabolic Disorders, 23, 107115.

Pirilä, S., Saarinen-Pihkala, U. M., Viljakainen, H., Turanlahti, M., Kajosaari, M., Mäkitie, O., \& Taskinen, M. (2012). Breastfeeding and determinants of adult body composition: A prospective study from birth to young adulthood. Hormone Research in Paediatrics, 77, 281-290.

Powls, A., Botting, N., Cooke, R. W. I., Pilling, D., \& Marlow, N. (1996). Growth impairment in very low birth-weight children at 12 years: Correlation with perinatal and outcome variables. Archives of Disease in Childhood, 75, F152F157.

Reilly, J. J., \& Dorosty, A. R. (1999). Epidemic of obesity in UK children. Lancet, 354, 1874-1875.

Saigal, S., Stoskopf, B., Streiner, D., Paneth, N., Pinelli, J., \& Boyle, M. (2006). Growth trajectories of extremely low birth weight infants from birth to young adulthood: A longitudinal, population-based study. Pediatric Research, 60, 751758.

Semmler, C., Ashcroft, J., van Jaarsveld, C. H. M., Carnell, S., \& Wardle, J. (2009). Development of overweight in children in relation to parental weight and socioeconomic status. Obesity, 17, 814-820.

Silventoinen, K., Bartels, M., Posthuma, D., Burk, G. F. E., Willemsen, G., Beijsterveldt, T. C. E. M., \& Boomsma, D. I. (2007). Genetic regulation of growth in height and weight from 3 to 12 years of age: A longitudinal study of Dutch twin children. Twin Research and Human Genetics, 10, 354363.

Silventoinen, K., \& Kaprio, J. (2009). Genetics of tracking of body mass index from birth to late middle age: Evidence from twin and family studies. Obesity Facts, 2, 196-202.

Silventoinen, K., Magnusson, P. K. E., Tynelius, P., Kaprio, J., \& Rasmussen, F. (2008). Heritability of body size and muscle strength in young adulthood: A study of one million Swedish men. Genetic Epidemiology, 10, 1-9.

Silventoinen, K., Pietiläinen, K. H., Tynelius, P., Sørensen, T. I. A., Kaprio, J., \& Rasmussen, F. (2007). Genetic and environmental factors in relative weight from birth to age 18: The Swedish young male twins study. International Journal of Obesity, 31, 615-621.

Silventoinen, K., Rokholm, B., Kaprio, J, \& Sørensen, T. I. A. (2010). The genetic and environmental influences on childhood obesity: A systematic review of twin and adoption studies. International Journal of Obesity, 34, 29-40.

Singhal, A., Fewtrell, M., Cole, T. J., \& Lucas, A. (2003). Low nutrient intake and early growth for later insulin resistance in adolescents born preterm. Lancet, 361, 1089-1097.

Sørensen, T. I. A., Holst, C., \& Stunkard, A. J. (2002). Childhood body mass index - Genetic and familial environmental influences in a longitudinal adoption study. International Journal of Obesity, 16, 705-714.

Wadhawan, R., Oh, W., Vohr, B. R., Wrage, L., Das, A., Bell, E. F., .. Higgins, R. D. (2011). Neurodevelopmental 
outcomes of triplets or higher-order extremely low birth weight infants. Pediatrics, 127, e654-e660.

WHO Expert Committee (1995). Physical status: The use and interpretation of authropometry (WHO Technical Reports Series). Geneva: WHO.

Wilson, R. S. (1979). Twin growth: Initial deficit, recovery, and trends in concordance from birth to nine years. Annals of Human Biology, 6, 205-220.

Yokoyama, Y. (2013). The West Japan twins and higher order multiple births registry. Twin Research and Human Genetics, $16,231-236$.
Yokoyama, Y. M., Pitkäniemi, J., Kaprio, J., \& Silventoinen, K. (2012). Weight growth of triplet infants from birth to twelve years of age. Twin Research and Human Genetics, 15, 672-679.

Yokoyama, Y., Sugimoto, M., Pitkäniemi, J., Kaprio, J., \& Silventoinen, K. (2011). Height growth of triplets from birth to twelve years of age in Japan. Twin Research and Human Genetics, 14, 468-475.

Ziadeh, S. M. (2000). The outcome of triplet versus twin pregnancies. Gynecologic and Obstetric Investigation, 50, 96-99. 